\title{
A study to measure the impact of implementation of 5-S on pipe and profile: A case study of a pipe and profile maker
}

\author{
Hamidreza Karkehabadi $^{\mathrm{a}^{*}}$, Abolfazl Danaei ${ }^{\mathrm{b}}$ and Mehran Orouei
}

${ }^{a}$ Young Researchers and Elite Club, Semnan Branch, Islamic Azad University, Semnan, Iran

${ }^{b}$ Department of Management, Semnan Branch, Islamic Azad University, Semnan, Iran

\section{H R O N I C L E}

Article history:

Received January 15, 2013

Received in revised format

30 April 2013

Accepted May 42013

Available online

May 52013

Keywords:

$5-S$

Losses

Stop time

\section{A B S T R A C T}

Productivity improvement plays essential role on cost reduction and production planning in many organizations. There are literally various methods for measuring productivity and improving systems' capabilities such as total quality management, $5 \mathrm{~S}$, etc. In this paper, we perform an empirical investigation to find out whether implementing $5 \mathrm{~S}$ could reduce interruptions in production systems in one of pipe and profile manufacturing units located in province of Semnan, Iran. The proposed study compares the mean and standard deviations of waste materials before and after the implementation of 5-S in three different lines and statistical tests indicate that 5-S have made the necessary change on production planning and it could reduce waste materials, significantly.

(C) 2013 Growing Science Ltd. All rights reserved.

\section{Introduction}

For many years, there have been some major concerns to remove any waste materials generated in production planning. Waste management plays essential role on increasing productivity, productivity and contributing on production of environment friendly products. There are literally tremendous efforts on introducing various techniques to improve the quality of systems using managerial techniques. Mohammadshahi (2013) provided a comprehensive review on all methods and their applications combined with multi-criteria decision making techniques. Kazemi et al. (2012) designed organizational excellence model for one of cellulose industries in Iran. They determined its components and aspects, prioritized the aspects and components and analyzed relationship among various characteristics of organizational excellence model in this industry. Kaplan and Norton (1992) are believed to be the first people who introduced the idea of balance score card (BSC) for improving the performance of organizations.

*Corresponding author. Tel: +98 9125314901

E-mail addresses: hamid15465@yahoo.com (H. Karkehabadi) 
According to Kaplan and Norton (1996, 2000), an organization must be considered beyond just financial figures. Mozaffari et al. (2013) used BSC for performance evaluation system of Islamic Azad University of Semnan and they utilized a strategy map to reach the necessary objectives. Hemati and Mardani (2012) designed a performance appraisal system based on balanced scorecard for improving productivity. Huang (2009) designed a knowledge-based system for strategic planning using a balanced scorecard perspective.

Control chars are another techniques for measuring the quality of production planning. Tan-intara-art and Rojanarowan (2013) presented a framework for prioritization and selection of parameters for control chart implementation based on technical criticality and cost criticality. Osta and Naderi (2012) implemented fuzzy analytic network process in quality function deployment model. They proposed an empirical investigation of QFD implementation when fuzzy numbers were implemented to handle the uncertainty associated with various components of the proposed model. They used fuzzy analytical network to detect the relative importance of different criteria and using fuzzy numbers they calculated the relative importance of these factors. The results of using fuzzy analysis network process based on the QFD model in Daroupat packaging company showed that the most important indexes were being waterproof, resistant pill packages, and production cost.

The proposed study of this paper uses 5-S (Ideas, 2011) as an empirical method for reducing wastes in production system. The organization of this paper first presents details of the survey in section 2 while the results of testing the effects of the implementation of 5-S before and after were investigated in section 3 and finally, concluding remarks are given in the last to summarize the contribution of this paper.

\section{The proposed study}

The proposed study of this paper uses Independent-Sample $\mathrm{T}$ Test to compare the mean of wastes before and after the implementation of 5-S. We also use Levene test to compare the variances of two sample tests before and after the implementation of 5-S. The first hypothesis of this survey is as follows,

1. The implementation of 5-S reduces wastes materials in production planning of the proposed case study of pipe and profile unit.

2. The implementation of 5-S reduces interruption in production planning of the proposed case study of pipe and profile unit.

The study compares the statistics in three different lines of productions.

\section{The results}

In this section, we present details of findings on comparing the amount wastes generated before/after 5-S implementation. Table 1 demonstrates the results of $t$-student test on comparing two groups of data.

\section{Table 1}

The results of some basic statistics before/after 5-S implementation in terms of the number of wastes

\begin{tabular}{cccccc}
\hline Production line & 5S Implementation & Numbers & Mean & Standard deviation & Deviation from mean \\
\hline \multirow{2}{*}{ Line 1 } & Before & 183 & 0.45 & 0.67 & 0.049 \\
& After & 175 & 0.31 & 0.57 & 0.043 \\
\hline \multirow{2}{*}{ Line 2 } & Before & 172 & 0.999 & 2.952 & 0.225 \\
& After & 196 & 0.159 & 0.792 & 0.056 \\
\hline \multirow{2}{*}{ Forge line } & Before & 229 & 1.15 & 2.687 & 0.177 \\
& After & 180 & 0.099 & 0.298 & 0.022 \\
\hline
\end{tabular}


As we can observe from the results of Table 1, there are some reductions on the average amount of wastes before and after the implementation of $5 \mathrm{~S}$. There are some significant changes on standard deviations of the data. Table 2 demonstrates the results of performing fisher test on before and after performing systems.

Table 2

The results of Fisher test for the first hypothesis

\begin{tabular}{cccccc}
\hline Production line & F-test & F-value & P-value & t-value & P-value \\
\hline \multirow{2}{*}{ Line 1 } & $\sigma_{\mathrm{B}}=\sigma_{\mathrm{A}}$ & 2.00 & 0.158 & 2.07 & 0.039 \\
& $\sigma_{\mathrm{B} \neq} \sigma_{\mathrm{A}}$ & - & - & 2.078 & 0.038 \\
\hline \multirow{2}{*}{ Line 2 } & $\sigma_{\mathrm{B}=\sigma_{\mathrm{A}}}$ & 22.77 & 0.000 & 3.829 & 0.000 \\
& $\sigma_{\mathrm{B} \neq} \sigma_{\mathrm{A}}$ & - & - & 3.681 & 0.000 \\
\hline \multirow{2}{*}{ Forge line } & $\sigma_{\mathrm{B}=} \sigma_{\mathrm{A}}$ & 34.19 & 0.000 & 5.225 & 0.000 \\
& $\sigma_{\mathrm{B} \neq} \sigma_{\mathrm{A}}$ & - & - & 5.878 & 0.000 \\
\hline
\end{tabular}

As we observe from the results of Table 2, F-value is meaningful for the second line and the third line, which means the variances of two groups are not equal. On the other hand, t-values for all three groups are meaningful when the level of significance is five percent. Therefore, we can conclude that implementation of 5 -S has been able to influence on reducing wastes materials and the first hypothesis has been confirmed.

In order to test the second hypothesis, we compare the mean of wastes materials compared with total production in terms of minutes of production as a measure of production interruption. Table 3 demonstrates the results of our findings,

Table 3

The results of statistics before/after $5 \mathrm{~S}$ implementation in terms of minutes of waste production

\begin{tabular}{cccccc}
\hline Production line & 5S Implementation & Numbers & Mean & Standard deviation & Deviation from mean \\
\hline \multirow{2}{*}{ Line 1 } & Before & 183 & 19.10 & 17.29 & 1.278 \\
& After & 175 & 8.20 & 8.269 & 0.625 \\
\hline \multirow{2}{*}{ Line 2 } & Before & 172 & 1.999 & 17.050 & 1.300 \\
& After & 196 & 0.458 & 17.432 & 1.245 \\
\hline \multirow{2}{*}{ Forge line } & Before & 229 & 2.096 & 21.888 & 1.446 \\
& After & 180 & 1.544 & 20.171 & 1.503 \\
\hline
\end{tabular}

Similar to the first hypothesis, there is a significant reduction on mean of three lines after $5 \mathrm{~S}$ operations are executed. Table 4 shows the results of performing fisher test on before and after performing systems.

Table 4

The results of Fisher test for the second hypothesis

\begin{tabular}{cccccc}
\hline Production line & F-test & F-value & P-value & t-value & P-value \\
\hline \multirow{2}{*}{ Line 1 } & $\sigma_{\mathrm{B}=\sigma_{\mathrm{A}}}$ & 51.83 & 0.000 & 7.58 & 0.000 \\
& $\sigma_{\mathrm{B} \neq} \sigma_{\mathrm{A}}$ & - & - & 7.69 & 0.000 \\
\hline \multirow{2}{*}{ Line 2 } & $\sigma_{\mathrm{B}=\sigma_{\mathrm{A}}}$ & 0.069 & 0.792 & 3.002 & 0.0028 \\
& $\sigma_{\mathrm{B} \neq} \sigma_{\mathrm{A}}$ & - & - & 3.007 & 0.0028 \\
\hline \multirow{2}{*}{ Forge line } & $\sigma_{\mathrm{B}=\sigma_{\mathrm{A}}}$ & 0.051 & 0.82 & 2.622 & 0.009 \\
& $\sigma_{\mathrm{B} \neq} \sigma_{\mathrm{A}}$ & - & - & 2.648 & 0.008 \\
\hline
\end{tabular}


In terms of F-value, the results are similar to the first hypothesis and the null hypotheses for the second line and third one are rejected. However, when we look at the t-values all three null hypotheses are rejected, which means we can reject the null hypotheses and conclude that implementation of $5 \mathrm{~S}$ has reduced interruptions.

\section{Conclusion}

We have presented an empirical investigation on the effects of the implementation of $5 \mathrm{~S}$ on reducing wastes materials as well as interruptions. The proposed study has been implemented in one of manufacturing units of pipe and profile located in province of Semnan, Iran. The results of our survey have indicated that $5 \mathrm{~S}$ was capable of wastes reduction. The study has also concluded $5 \mathrm{~S}$ has been able to reduce production interruption, significantly.

\section{References}

Hemati, M \& Mardani, M. (2012). Designing a performance appraisal system based on balanced scorecard for improving productivity: Case study in Semnan technology and science park. Management Science Letters, 2(5), 1619-1630.

Huang, H.C. (2009). Designing a knowledge-based system for strategic planning: A balanced scorecard perspective. Expert System with Applications, 36(1), 209-218.

Ideas, I. (2011). Parenting Under 5s: Strategies for Raising Young Children. Infinite Ideas.

Kaplan, R. S. \& Norton, D, P. (2000). Having trouble with your strategy? Then map it. Harvard Business Review, 42-134.

Kaplan, R, S. \& Norton, D, P. (1992). The Balanced Scorecard: Measures That Drive Performance, Harvard Business Review, 71-75.

Kaplan, R, S. \& Norton, D, P. (1996). Translating Strategy into Action the Balanced Scorecard. Harvard Business School Press, Boston.

Kazemi, S., Sadaghani, J., Nikokar, G \& Sadeghi, M. (2012). Designing organizational excellence model for cellulose industry of Iran. Management Science Letters , 2(1), 107-112.

Mohammadshahi, Y. (2013). A state-of-art survey on TQM applications using MCDM techniques. Decision Science Letters, 2(3), 125-134.

Mozaffari, A., Kalaei, H., Shahhosseini, M \& Chaghouee, Y. (2013). A new framework for performance evaluation system using strategy map: A case study of Islamic Azad University of Semnan. Management Science Letters, 3(4), 1041-1048.

Osta, S \& Naderi, H. (2012). Applying fuzzy analytic network process in quality function deployment model. Management Science Letters , 2(4), 1325-1340.

Tan-intara-art, S \& Rojanarowan, N. (2013). Prioritization and selection of parameters for control chart implementation based on technical criticality and cost criticality. Decision Science Letters, 2(3), 203-210. 